\title{
Makrokosmos II
}

\author{
Roomet Jakapi, Enn Kasak
}

\begin{abstract}
Teesid
17.-18. sajandi mõtlemisele oli iseloomulik põimida pühakirja mõtlemine teadusliku mõtlemisega. Inglane William Whiston oli teatud mõttes tüüpiline selle aja mõtleja, kelles olid ühendatud loodusteadlane, teoloog ja filosoof. Mõtlemine ise oli arenenud nii kaugele, et oli olemas ettekujutus kehast ja hingest. Kui inimene oma mõistust õigesti rakendab, jõuab ta nii või teisiti teadmiseni sellest, et eksisteerib üks ja ainus kõigeväeline Jumal, kes on maailma loonud. Samuti jõuab ta järelduseni, et tema hing on surematu ja et on olemas surmajärgne elu. Milline see surmajärgne elu täpselt on, jääb saladuseks. Katoliiklased leidsid endiselt, et maisest kehast lahkudes läheb hing puhastustulle, purgatooriumi. Anglikaani kiriku seisukoha järgi ei põhine õpetus purgatooriumist Piiblil, mistõttu öeldakse sellest lahti.
\end{abstract}

Märksõnad: alkeemia, anglikaani kirik, hingede rändamine, religioon, pärispatt, teadus, teaduse ajalugu

Enn Kasak: Eelmine kord piiritlesime, mille poolest makrokosmos erineb päris kosmosest, jõudsime niikaugele, et makrokosmos on see osa kosmosest, mis on mõttetu ilma inimeseta, ja leidsime ka sellised struktuurielemendid nagu taevas ja põrgu - kohad, kuhu inimese hing peaks minema pärast surma, ja võib-olla ka kohad, kus hing asub enne seda, kui ta inimesesse tuleb. Lisaks arutlesime, et see makrokosmos tuleb võib-olla kõige ehedamal kujul esile kusagil uusaja alguses ja teaduse alguse perioodil. Sestap lubasime rääkida Inglismaa uusajast, täpsemalt perioodist 1650-1750.

Roomet Jakapi: Kõnealuse perioodi teaduslikule mõtlemisele oli iseloomulik põimuda religioosse (pühakirjal põhineva) mõtlemisega.

Enn Kasak: Ja isegi nii, et pühakiri oli pigem tähtsam tõeallikas kui teadus. Teadus oli meetod tõe hankimiseks, aga tõde ennast võis pigem otsida pühakirjast.

Roomet Jakapi: Tooksin nüüd konkreetse näite teaduse ja religiooni lähedusest ja kokkukuuluvusest sel perioodil. Inglane William Whiston oli teatud mõttes tüüpiline 17.-18. sajandi keskpaiga mõtleja, kelles olid ühendatud loodusteadlane, teoloog ja filosoof. Aastal 1717 avaldas ta raamatu pealkirjaga "Loomuliku ja ilmu-

http://haldjas.folklore.ee/tagused/nr26/makro.pdf 
tatud religiooni astronoomilised printsiibid". Tollal pandi raamatutele sageli pikki pealkirju, see siin on suhteliselt lühike. Ometi sisaldub juba raamatu pealkirjas paljugi huvitavat. Mida mõeldakse siin loomuliku ja ilmutatud religiooni all? Loomulik religioon on niisugune religioon, milleni inimesel on võimalik jõuda korrektse mõistusarutelu teel (ilma jumaliku ilmutuse abita). Kui inimene oma mõistuse väge õigesti rakendab, jõuab ta nii või teisiti tõsikindla teadmiseni sellest, et eksisteerib üks ja ainus kõigeväeline Jumal, kes on selle maailma loonud. Sarnaselt jõuab inimene järelduseni, et tema (mittemateriaalne) hing on surematu ja et on olemas surmajärgne elu. Milline see surmajärgne elu täpselt on, jääb saladuseks, ent on teada, et teispoolsuses saavad inimesele osaks kas naudingud või karistused, vastavalt sellele, kui hästi või halvasti, õigesti või valesti on ta maises elus käitunud ja mõtelnud. Ilmutatud religiooni all peetakse aga silmas eelkõige sääraseid jumalikke tõdesid, mida saab välja lugeda pühakirjast, ent milleni inimene pelgalt oma mõistusega (ilma jumaliku ilmutuseta) ei jõua. Näiteks sellised tõed, et Jumal on kolmainus või et viimsel kohtupäeval toimub surnute ülestõusmine. Siia kuulub ka õpetus pärispatust.

Enn Kasak: Oot, inimene, kes ei ole religioosset kasvatust saanud, võib siin sattuda raskustesse, arusaamisraskustesse. Küsimus on ju selles, mis on siis pärispatt. Kui laps sünnib, siis pärispatu teooria järgi on ta juba patune. Tänapäeva inimene vaidleb sellele tihti vastu, sest milles siis avaldub väikese lapse patusus, kui ta pole mingit pattu teinud. Lähtudes pärispatu seisukohast on lood nii, et oma loomult on laps ikkagi patune. See hakkab avalduma juba maastmadalast, väikestel lastelgi on juba teatud kalduvused ja õelused sees. Nad ei suuda veel pattu teha, aga kui nad suudaksid, siis nad teeksid. Ning seda sellepärast, et nende kui inimeste loomus on rikutud. See ongi pärispatt, mida inimkond kannab. Pärispatu saime kaela juba siis, kui Eeva ja Aadam sõid keelatud vilja, vastandades oma tahte Jumala tahtele, ning sellega on inimene kui universaal, inimene kui tervik ära tõuganud Jumala ja ilma Jumala abita pole tal mingisugust lootust olukorrast välja tulla.

Roomet Jakapi: Enamikule tänapäeva eurooplastest võib see õpetus tunduda vägagi imelik ja vastuvõetamatu, aga tollal oli see täiesti tavaline, normaalne arusaam. Tulles tagasi W. Whistoni raamatu pealkirja juurde - "Loomuliku ja ilmutatud religiooni astronoomilised printsiibid", tuleks tähele panna ka selle tagumist poolt. Meie 
ajal võidakse arvata, et astronoomia on teadus, mille seostamine või põimimine religiooniga on ülimalt kahtlane ja rumal tegu. W. Whistoni raamatus on juba pealkirjast alates ühendatud religioossed tõed ja teaduslik arutelu. Tema kasutab teaduslikke argumente põhjendamaks loomuliku ja ilmutatud religiooni õpetusi.

Enn Kasak: Siin võiks öelda nii, et kui inimene arutleb nende tõdede üle, siis miks ta ei peaks kasutama oma mõistust. Ta kasutab oma mõistust ja teeb seda parimal viisil. Ja parim viis tundub olevat teaduslik viis. Järelikult on täiesti normaalne, et kui rääkida pühakirjast, siis peaks rääkima sellest teaduslikult. Nende ühendamine pole vähimalgi määral kunstlik, vaid see on lausa paratamatu.

Roomet Jakapi: Teisiti öeldes, pühakiri annab ette teatavad maailmavaatelised raamid, mille sees toimub see teaduslik arutelu. Nüüd siis paar huvitavat argumenti W. Whistonilt. Esimene puudutab tollal levinud arusaama, et Maa on kuus-seitse tuhat aastat vana. William Whiston kaitses seda (tema meelest piibellikku) seisukohta ühe (teaduslikku laadi) vastuväite eest. Nimelt oli hiljaaegu väidetud, et maailmamere vesi pidi oma tollase soolasuse taseme saavutama väga-väga pika aja jooksul.

Enn Kasak: Võib-olla siin peaks selgitama, kuidas see soolasus tekib. Kui nüüd maailmameri on algselt koos maaga loodud, siis loomise järgselt oli vesi mage. On teada, et jõed kannavad pidevalt merre soola. Kuigi jõevesi tundub meile mage, ei ole ta ju mitte destilleeritud vesi, vaid sisaldab endas soolalahuseid. Ja kui nüüd vesi aurustub, siis jääb jõgede poolt merre kantud sool sinna alles. Pika aja jooksul koguneb jõgede poolt kantud sool merre ja niimoodi muutubki meri soolaseks. See osa soola, mida meri ise lahustada suudab, on jõgede osaga võrreldes kaunis tühine. On võimalik tõesti välja rehkendada, kui palju aega võiks kuluda maailmamere soolasuse tõusmiseks praeguse tasemeni. Teades näiteks jõgede voolu hulka ja keskmist soolasust, on see n-ö põhikooli ülesanne.

Roomet Jakapi: Ja nii siis väidetigi, et aeg, mis on kulunud merevee soolasuse tekkeks, pidi olema palju pikem kui kuus-seitse tuhat aastat.

Enn Kasak: Ja tänapäeval ongi rehkendatud, et see peab ikka kindlasti olema miljoneid aastaid. 
Roomet Jakapi: W. Whistoni jaoks olnuks säärane arvamus absurdne ja vastuvõetamatu. Tema väitel on jutt ülipikast maailmamere vee soolaseks muutumise ajast kõigest ebakindel hüpotees, mille kinnituseks ei leidu vähimatki tõendusmaterjali.

Enn Kasak: Kusagil pole ju kirjas, et meri pidi alguses mage olema. Selles mõttes ongi kõnealune väide üksnes hüpotees.

Roomet Jakapi: William Whiston kaitses tavapärast Piiblist tuletatud seisukohta ja püüdis kummutada sellele vastanduvat arvamust. Ta on tuntud selle poolest, et seletas mitmeid pühakirjas kirjeldatud sündmusi komeetide abil, kuigi mõned tema säravatest ideedest olid teistelt laenatud. Igatahes väitis ta oma arvutuste põhjal, et aastal 2348 eKr lähenes Maale üks komeet ning põhjustas suure veeuputuse, millest jutustatakse 1. Moosese raamatu 6.8. peatükis. W. Whistoni järgi oli tegemist sama komeediga, mida nähti viimati aastal 1680 .

Enn Kasak: Siin võiks tähele panna, et kui jutt on ookeani soolasusest, siis ütleb W. Whiston otse ja selgelt välja, et tegemist on tõestamatu hüpoteesiga. Aga kui jutt on veeuputusest, siis on tema arvates tegemist väga tõenäolise olukorraga ning see näitab, et arutluse lähtepunkt on erinev. Ühel juhul ollakse veendunud, et Maa peab olema kuus-seitse tuhat aastat vana ja kui keegi argumenteerib selle väite vastu, peab ta esile tooma erakordselt tugevad argumendid. Aga kui väita, et oli veeuputus, siis see ei ole ju kahtluse all, küsimuseks võib olla vaid veeuputust tekitanud nähtuse olemus. Kui võtta nii, et oleme hiljaaegu teada saanud, et on olemas sellised toredad nähtused nagu komeedid, mis põhjustavad palju huvitavaid asju, siis on täiesti ilmne, et komeedid põhjustasid veeuputuse. Selline arutluskäik on mõnes mõttes väga õpetlik, sest nii ei mõeldud ainult uusajal. Sama tuleb sageli ette ka tänapäeval, mil kõik teooriad, mis on kooskõlas n-ö normaalse maailmanägemusega, ei vaja erilist põhjendamist, vaid nad tunduvad lausa tõenäolised või peaaegu õiged juba esimesel väljaütlemisel ning neid kritiseeritakse ehk üksnes moepärast. Kõik teised teooriad aga jäävad pigem hüpoteesideks, ka pärast seda, kui nende kasuks on võimalik esitada mõjukaid argumente.

Nii et tõde on tänapäevalgi enne juba teada ja pärast üritame seda tõde teadusliku meetodi abil tõestada. Uusajal oli see täiesti 
normaalne tegevusviis ja on seda tänapäevalgi, kuid praegu peetakse heaks tooniks varjuda objektiivsuse maski taha.

Võib-olla oleks nüüd paras aeg minna konkreetsete probleemide juurde. Eelmises osas lubasime rääkida makrokosmose struktuurielementidest. Nimetasime konkreetselt põrgut ja taevast. Kuid enne peaks käsitlema küsimust, mis seondub põrgu ja taevaga. Teatavasti on inimene mullast võetud, kõnnib maa peal ja saab uuesti mullaks. Ja mis asi see siis on, mis põrgusse või taevasse läheb? Teiste sõnadega, tekib küsimus hingest ja kehast. Neist asjust pole tänapäeval kombeks rääkida, või kui on, siis vist väga kindlas kontekstis.

Roomet Jakapi: Jah, siinkohal võiks tuua ühe meie ajale iseloomuliku näite, mille leidsin hiljuti ilmunud gümnaasiumi psühholoogiaõpikust (Psühholoogia gümnaasiumile, Tartu Ülikooli Kirjastus 2002).

Enn Kasak: Mille väärtushinnanguid me kuidagi kahtluse alla ei pane.

Roomet Jakapi: See on suurepärane õpik, mida soovitaksin eriti lugeda filosoofidel. Juba esimese peatüki teises lõigus käsitletakse traditsioonilist hinge ja keha probleemi. Tegemist on teatava ideoloogilise sissejuhatusega kogu raamatule:

Üheks vanimaks psühholoogiaprobleemiks on keha ja hinge suhe. Kuigi paljud on aegade jooksul uskunud, et hing võib kehast irduda ja elada iseseisvat elu, ei pea teaduslik psühholoogia seda seisukohta usutavaks, kuna selle kohta puuduvad tõsiselt võetavad andmed ehk teaduslikud faktid. Olemasolevad tõendid kõnelevad selle kasuks, et mõistus ja tunded tekivad inimese ajus ning lakkavad toimimast koos ajutegevuse kustumisega. Inimese hing saavutab surematuse hoopis kultuuri kaudu: inimese mõtted, mälestused ja tunded elavad edasi, kui nad on jäädvustatud kirjas või mõnel muul pärandataval viisil.

Seda lõiku ja eriti viimast lauset esmakordselt lugedes tuli mu näole sügav muie. Inimene sureb, aga tema hing saavutab surematuse, sest tema mõtted ja mälestused elavad (kusagile jäädvustatult) edasi... Kui lisaksime siia, et kadunuke elab edasi oma lastes ja lastelastes jne, siis mida see meenutab? 
Enn Kasak: Ilmalikud matused.

Roomet Jakapi: Just nimelt, need on ilmalikud matused. Gümnaasiumiõpilased juhatatakse inimpsühholoogiasse sisse ilmaliku matusetseremooniaga. (Loodetavasti ikka tohib niimoodi heatahtlikult ironiseerida.)

Enn Kasak: Siit ilmneb siis see, et inimene on tänapäeva seisukohalt võttes surelik, elab surelikuna, sureb surelikuna, ta on topeltsurelik.

Roomet Jakapi: Õpikus väidetakse, et inimese mõtted ja mälestused elavad ka pärast tema surma edasi, nimelt siis, kui need mõtted ja mälestused on kuidagi jäädvustatud, aga inimene ise (või tema hing) ei ela edasi.

Enn Kasak: No see on täiesti normaalne seisukoht.

Roomet Jakapi: Kahtlemata, muidu ei avaldataks seda kooliõpikus. See on kõige tavapärasem ja pealegi teadusliku põhjaga seisukoht.

Enn Kasak: Jah, kuigi on väga küsitav, kas siin teadus midagi lausa ära tõestanud on, kuid see on hoopis teine probleem. Aga tuleme nüüd tagasi normaalsuse juurde, vaatleme igapäevast praktilist normaalsust. Näiteks kui suvaline inimene läheb ja lööb varba vastu kivi. Siis saab ta teadlikuks kahest asjast: on olemas kivi ja on olemas valu varbas. Ja ilmselt see kivi ei ole valu ja valu ei ole kivi. Need on täiesti erinevad asjad. Võib osutuda veel, et seda kivi nägi ta unes, kuid ta ärkab üles ja avastab, et tal on varvas magades kuhugi vahele jäänud ja valu oli ikkagi päriselt olemas. Ilmneb, et on tegemist kahe erineva nähtusega. Ja teatud aegadel ja väga kaua aega oligi normaalne ja täiesti iseenesestmõistetav, et neid nähtusi lahutati. Täpselt samamoodi nagu tänapäeval on kombeks neid samastada.

Roomet Jakapi: See juhatab meid tagasi selle perioodi juurde, mida me siin käsitleme. Vastupidiselt tänapäevale oli tollal täiesti normaalne uskuda, et varem või hiljem, ühel või teisel moel läheb elu pärast surma edasi. 
Enn Kasak: Tollal kuulutati inimesele, et tal on mängida väga eriline osa ja et tema elu läheb pärast surma edasi, ning see oli normaalne seisukoht. Ja kas ei tundu see kuidagi ülevam olevat kui tänapäevane seisukoht?

Roomet Jakapi: Võib-olla me ei peaks siin võtma üht- ega teistpidi hoiakut ega püüdmagi väärtustada. Aga kindlasti tuleb siit välja põhimõtteline erinevus tollaste ja praeguste arusaamade vahel.

Enn Kasak: Ma ei tahtnudki väärtustada, vaid lihtsalt selgitada, miks on arusaadav, kui inimesed sellisest hoiakust kinni peavad. Inimesele meeldib näha keha ja hinge pigem eraldiseisvana, mitte ühe ja samana.

Roomet Jakapi: Jah, see arusaam või usk või teadmine, et elu läheb pärast surma edasi, näib tõesti meeldivam ning 17.-18. sajandil peeti seda reeglina ka mõistuspäraseks ja põhjendatuks.

Enn Kasak: Ega mõtlejale endale ei pruugigi nii väga meeldida see arusaam, et hing jääb kestma ja temaga pärast midagi juhtub. Ma tahan rõhutada, et mõtleja oli tollal enda arvates kuidagi objektiivses sundseisus. Talle see võib-olla isiklikult ei meeldinud, kuid ta pidi tunnistama, et on normaalne uskuda, et inimese hing on võimeline elama kauem kui keha. Ning see on väga hirmutav.

Roomet Jakapi: Kui tunnistada, et surmajärgne elu on olemas, siis seoses sellesama hinge ja keha vahekorra probleemiga tekib siit igasuguseid huvitavaid küsimusi. Näiteks, kui möönda, et pärast inimese surma väljub tema hing kehast, siis kohe tekib küsimus, kuhu see hing satub. Kus siin universumis on maisest kehast lahkunud hingede koht?

Enn Kasak: Uusajaks on taastunud arusaam universumi ühtsusest. Kuni Giordano Brunoni arvati, et Kuu orbiidist kõrgemale jääv maailm on tehtud täiesti erinevast materjalist võrreldes kuualuse maailmaga. Bruno kosmoloogiline printsiip, mille ühe aspekti kohaselt koosneb terve universum ühest ja samast mateeriast, oli meid huvitaval perioodil üldiselt omaks võetud. Ja kui siis räägiti põrgust, taevast ja hingede rännakust, siis neid ei käsitletud enamasti (kuid sugugi mitte alati) mingi rännakuna kusagil teistes dimensioonides, nagu tänapäeval kõlbaks öelda, või mingis teispool- 
suses, vaid hinge rännakud toimuvad ikka sellessamas universumis, mis on oma olemuselt ühtne.

Roomet Jakapi: Üks probleem, mida me käsitleda tahame, on põrgu asukoht universumis. Samuti vajab selgitamist, kus on taevas, õndsate hingede lõplik asupaik.

Enn Kasak: Nüüd jõudsime niikaugele, et on olemas hing ja on olemas keha. Hing on see, mis keha liigutab. Kui keha õnnetukene ära laguneb, jääb hing alles ja peab sellessamas universumis kuhugi minema.

Roomet Jakapi: Selle ajastu kontekstis, millest me räägime, on need väga tõsised küsimused, ükskõik kui kohatud või kummalised need tänapäeval ka ei tundu.

Enn Kasak: Tolle ajastu teadlane ei saa teha tõsiselt võetavat kosmoloogiat, ilma et ta vastaks nendele küsimustele.

Roomet Jakapi: Just, sest nii või teisiti puutub ta kokku selle religioosse raamiga, mille sees ta mõtleb.

Enn Kasak: Aga enne veel, kui minna hingede rännaku juurde, peaks natukene siiski käsitlema hinge-keha dualismi teooriaid. Mis siis hingega ikkagi juhtub, kuidas avaldub hinge surematus, mis seisundis on hing sellest hetkest alates, kui keha laguneb.

Roomet Jakapi: Vastavaid õpetusi oli tollal vägagi erinevaid. Katoliiklased leidsid muidugi endiselt, et maisest kehast lahkudes läheb hing puhastustulle, purgatooriumi. Aga 17.-18. sajandi Inglismaa puhul on meil tegemist valdavalt protestantliku maailmaga. Anglikaani kiriku ametliku seisukoha järgi ei põhine õpetus purgatooriumist Piiblil, mistõttu öeldakse sest õpetusest lahti.

Enn Kasak: Sellega seondub üks väga huvitav analoogia. Sedasama puhastustule protsessi näiteks seostati alkeemiaga. On joonistatud ilus pilt, kus käsitletakse universumit alkeemiku destillatsiooniahju analoogina. Inimese hing on seal keskel, kesk leeki, seda küpsetatakse ja temast eraldub kõik halb tuhana ning vajub alla tuhakasti, mille juurde on kirjutatud Saatan. Ja n-ö puhastunud osa hingest, ehk siis destilleeritud aine, kerkib üles Jumala juurde. 
Roomet Jakapi: Kui aga puhastustuld ei tunnistata, siis kerkib teravasti esile küsimus, mis siis ikkagi hingest saab, kui ta kehast eraldub.

Enn Kasak: Sest puhastustuli kuulub tõesti katoliiklikku traditsiooni. Tema järgi tekib vajadus, kui hakata arutlema, kas väiksemat sorti pattu teinud inimene peaks kohe igaveseks hukka mõistetud saama. Aga puhastustuld ei ole mainitud kusagil algses pühakirjas. Tagasi pöördudes algse pühakirja juurde tuli anglikaani kirikus puhastustule õpetus kõrvale jätta.

Roomet Jakapi: Nagu ma ennist ütlesin, kui hing peaks kehast eralduma, siis üks küsimus on see, kuhu ta satub, aga siin kerkib ka teine oluline küsimus, nimelt, missuguses olekus see hing on. Kujutage ette, et hingel pole enam keha kasutada, ta ei ole enam seotud meeleorganite ega ajuga ja ometi ta eksisteerib. Tänapäeva psühholoogia seisukohalt on see mõeldamatu. Arvamus, et hing võiks midagi tunda või tajuda ilma ajuta, kehast väljununa vms, ei mahu nüüdisaegse teadusliku maailmaraami sisse.

Enn Kasak: Tänapäeval ollakse arvamusel, et see toimub kõik ainult aju kaudu, aga tollel ajal oli arusaam, et ajul ei pea olema sellist funktsiooni.

Roomet Jakapi: Mööndes, et hing saab kehast eralduda, tekib küsimus, kas ta säärases olekus ka midagi tunneb ja kogeb. Mida ja kuidas? Whistoni ja Newtoni ajal arutleti muu hulgas selle üle, kas mõned hinge võimed selles olekus säilivad. Kas näiteks mälu on alles, kui hing on kehast eraldunud? Ametlik seisukoht oli igatahes selline, et kehast eraldunud hing ei hävi ning on ärkvel. Samas leidus teisitimõtlejaid, kes väitsid, et hing on selles olekus magav. Pikk unenäota uni.

Enn Kasak: Viimse kohtupäevani.

Roomet Jakapi: Ja lõpuks oli muidugi seisukoht, mis näikse kokku sobivat pühakirjaga, aga mitte nii hästi anglikaani kiriku ametliku doktriiniga. Selle seisukoha järgi ei ole hing midagi muud kui eluhingus, mis on materiaalsesse kehasse sisse puhutud, nõnda, et hing ei saa ilma kehata eksisteerida.

Enn Kasak: Pigem vanatestamentlik lähenemine asjale. 
Roomet Jakapi: Just. See oli siis põgus ülevaade võimalustest hinge ja keha rännaku alguses.

Enn Kasak: Kuidas selle kehaga nüüd on? Praegu pole me keha kohta veel midagi rääkinud, ainult seda, et keha mullast võetakse ja mullaks saab. Aga mismoodi keha võiks veel rännata?

Roomet Jakapi: Tollal usuti, et tuleb surnute ülestõusmine ja viimne kohtupäev. Need, kes pooldasid seisukohta, et surma ja ülestõusmise vahepealsel ajal eksisteerib hing kehast eraldi, leidsid, et kui surnu üles tõuseb, siis ühendatakse tema hing uuesti kehaga. Kas üles peab tõusma seesama keha, mis maha maeti? Igatahes peab see olema sellesama inimese keha, kes kord maa peal elas. Siinkohal murdis loodusteaduslik mõtteviis väga tugevalt sisse. Tekkis rida teadusliku ja filosoofilise värvinguga probleeme ja tõlgendusvõimalusi. Kui rännak jõuab lõpule ja kuri inimene on jõudnud põrgusse, siis tollase arusaamise kohaselt saavad talle seal osaks nii hingelised kui kehalised karistused.

Enn Kasak: Järelikult on keha vajalik. Kuid isegi rahvajuttudes ironiseeriti, et vaat see mees pandi 20 hundi poolt nahka, küll oleks huvitav näha, kuidas see keha ükskord viimselpäeval kokku pannakse. See tähendab, et neid asju ei arutatud mitte üksnes professionaalsete mõtlejate ringis, vaid et see oli väga levinud arutluste teema ka väljaspool filosoofia kateedrit.

Roomet Jakapi: Kui inimene siiralt usub, et talle on antud lühike aeg elada selles kuue-seitsme tuhande aasta eest loodud maailmas ning peagi saab talle osaks kas igavene õndsus või igavene piin, siis ilmselt on kogu tema maine elu hoopis teistsugune.

Enn Kasak: Paljud mõtlejad uskusid Jumalat ikka väga siiralt, sellepärast nad tundsidki nii sügavat huvi ja nägid nii palju vaeva, rakendades rehkendamiseks kogu oma vaimujõu.

Kahjuks me ei suutnud seekord oma lubadust pidada. Me lubasime rääkida muu hulgas sellest, kus taevas ja põrgu asuvad, aga niikaugele me ei jõudnud. Küll aga jõudsime rääkida sellest, mida tollel ajal usuti, kuidas saadi aru, et on olemas keha ja hing. Me püüdsime veenda, et on väga tõsine probleem, mis saab kehast ja hingest pärast surma. Sellest, kus nad siis tegelikult rändama peavad, räägime loodetavasti järgmises numbris. 